\title{
Dermatosparaxis in two White Doper lambs in Brazil: case report
}

\author{
[Dermatosparaxis em dois cordeiros White Dorper no Brasil: relato de caso] \\ A.P.C. Silva ${ }^{1}$, J.P.S. Mol $^{1}$, C.A. Carvalho Junior ${ }^{1}$, \\ T.A. Paixão ${ }^{2}$, R.L. Santos ${ }^{1} *$ \\ ${ }^{1}$ Escola de Veterinária - Universidade Federal de Minas Gerais - Belo Horizonte, MG \\ ${ }^{2}$ Instituto de Ciências Biológicas - Universidade Federal de Minas Gerais - Belo Horizonte, MG
}

\begin{abstract}
Dermatosparaxis is a genetic disease that affects collagen maturation. This disease is characterized by marked impairment of the resistance of collagen fibers that leads to skin fragility, and it may affect several species. This is the first report of dermatosparaxis in sheep in Brazil. Clinically, two White Dorper lambs had multiple skin lacerations in the neck, dorsum and limbs. Transmission microscopy demonstrated irregular collagen fibers arranged in hieroglyphic shape and scanning electron microscopy demonstrated thin collagen fibrils that were not arranged in bundles as observed in the normal dermis. These findings are consistent with the diagnosis of dermatosparaxis.
\end{abstract}

Keywords: sheep, dermatosparaxis, collagen, skin

\section{RESUMO}

A dermatosparaxis é uma doença genética que afeta a maturação do colágeno. Essa doença é caracterizada por redução acentuada da resistência das fibras colágenas que leva à fragilidade da pele. Esse é o primeiro relato de dermatosparaxis em ovinos no Brasil. Clinicamente, dois cordeiros da raça White Dorper tiveram múltiplas lacerações na pele do pescoço, dorso e membros. A microscopia de transmissão demonstrou fibras de colágeno irregularares arranjadas em formato de hieroflifo, e a microscopia de varredura demonstrou fibras finas de colágeno não arranjadas em bandas como na derme do animal normal. Esses achados são consistentes com o diagnóstico de dermatosparaxis.

Palavras-chave: ovino, dermatosparaxis, colágeno, pele

\section{INTRODUCTION}

Dermatosparaxis is a genetic disease that affects collagen maturation. It is an autosomal recessive disorder of connective tissue that leads to fragility and hyperextensibility of the skin (Smith et al., 1992; Zhou et al., 2011).

Human patients with dermatosparaxis, which is also known as Ehlers-Danlos syndrome (EDS) type VII $\mathrm{C}$, have mutations in a pro-collagen-Nproteinase gene that results in a failure to convert type I pro-collagen to collagen, resulting in an accumulation of ribbon-type fibrils. This type of collagen fibrils does not provide resistance to the connective tissue causing extreme fragility of the skin (Smith et al., 1992). However, in addition to the type VII, other manifestations of EDS have also been recognized in human patients, which result in variable clinical manifestations, and have different genetic defects as determinants (Sinke et al., 1997). Dermatosparaxis has also been described in sheep, cattle, dogs, cats, horses, and rabbits (Fjolstad and Helle, 1974; Sinke et al., 1997; Kohler et al., 2002). In cattle, there may be a premature stop codon in exon 3 and deletion of a $17 \mathrm{bp}$ sequence in exon 2 of the procollagen I N proteinase gene (ADAMTS-2), which is associated with dermatosparaxis (Colige et al., 1999).

Recebido em 18 de maio de 2014

Aceito em 3 de abril de 2015

*Autor para correspondência (corresponding author)

E-mail: rsantos@vet.ufmg.br 
Dermatosparaxis has been reported in some sheep breeds, including Dorper (Zhou et al., 2011), White Dorper (Van Halderen and Green 1988; Vaatstra et al., 2011), Norwegian (Fjolstad and Helle, 1974), and Merino (Bavinton et al., 1985). In sheep, the disease is characterized by severe fragility of the skin, whereas in other species umbilical and diaphragmatic hernia, hypermobility of joints, blue discoloration of the sclera and vascular disease have also been reported (Colige et al., 1999). Here we describe the first reported cases of dermatosparaxis in Brazil affecting two White Dorper lambs.

\section{CASE REPORT}

Two out of nine lambs with approximately two weeks of age, generated through embryo transfer, and sons of the same ram and ewe, were born with marked cutaneous fragility. The skin of the affected lambs was prone to rupture and detachment from the adjacent muscular and connective tissues upon minimal manipulation. The affected lambs had 148 heart beats per minute, 35 breaths per minute, body temperature of $40^{\circ} \mathrm{C}$, and 10 minutes of coagulation time. Episcleral vessels were congested and all joints were moderately swollen. These lambs had multiple lacerations of the skin in the neck (Figure 1A), dorsum, and limbs (Figure 1B), with variable degrees of hemorrhage. One of the lambs died naturally, and the other was sedated with intramuscular xylazine $0.05 \mathrm{mg} / \mathrm{kg}$ (Copazine, Schering-Plough Coopers, Brazil), and euthanized with an overdose of intravenous sodium thiopental $(90 \mathrm{mg} / \mathrm{kg})$ (Cristalia, Brazil).

Grossly, both affected lambs had extensive lacerations of the skin in the limbs, dorsal and abdominal regions. These lacerations were between 7 and $12 \mathrm{~cm}$ in length, and were associated with hemorrhage and necrosis. There was abundant purulent exudate draining from the adjacent subcutaneous tissues, which was interpreted as phlegmons (Figure 1C). Superficial lymph nodes were moderately enlarged. Humero-radio-ulnar and femur-tibio- patellar joints were bilaterally and moderately enlarged. The articular capsules were thickened, and there was accumulation of moderate amounts of purulent exudate (purulent arthritis).

Fragments of the skin of affected lambs were collected during necropsy, and a skin biopsy from a non-affected lamb was used as a control. These fragments were processed for histopathology, transmission and scanning electron microscopy. For histopathology, fragments were fixed in $10 \%$ buffered formalin for $24 \mathrm{~h}$, embedded in paraffin, sectioned at $5 \mu \mathrm{m}$, and stained with hematoxylin and eosin, Masson's tricromic, and picro sirius. For scanning and transmission electron microscopy, samples were fixed by immersion in Karnovsky solution (2\% paraformoldehyde and $2.5 \%$ glutaraldehyde) in $0.1 \mathrm{M}$ sodium cacodylate buffer overnight at $4^{\circ} \mathrm{C}$. For transmission microscopy, samples were stained overnight at $4^{\circ} \mathrm{C}$ in a saturated uranyl acetate solution, dehydrated in increasing concentrations of ethanol and propylene oxide, and embedded in Epon Araldite. Thin sections were stained with toluidine blue and examined under a light microscope for selection of fields. Blocks were trimmed, and thin sections $(60-90 \mathrm{~nm})$ were cut in an ultramicrotome (Leica EM UC6, Austria) mounted onto copper grids, stained with uranyl acetate and lead citrate, and examined with a transmission electron microscope (Tecnai G2-12$120 \mathrm{KV}$ - FEI SpriritBiotwin, USA). For scanning electron microscopy, after fixation, tissue samples were washed three times with 0.1 $\mathrm{M}$ sodium cacodylate buffer and post fixed for 2 hours at $4^{\circ} \mathrm{C}$ with $1 \%$ osmium tetroxide in $0.1 \mathrm{M}$ sodium cacodylate buffer. Samples were dehydrated in increasing concentrations of ethanol, and embedded in poly/bed 812 (Polysciences, Warrington, Pennsylvania). Thin sections (500 $\AA$ ) were cut with a diamond knife, collected on single-hole Formvar-coated grids, stained with uranyl acetate and lead citrate, and examined with a scanning electron microscope (JEOL JSM - 6360LV, Japan). 

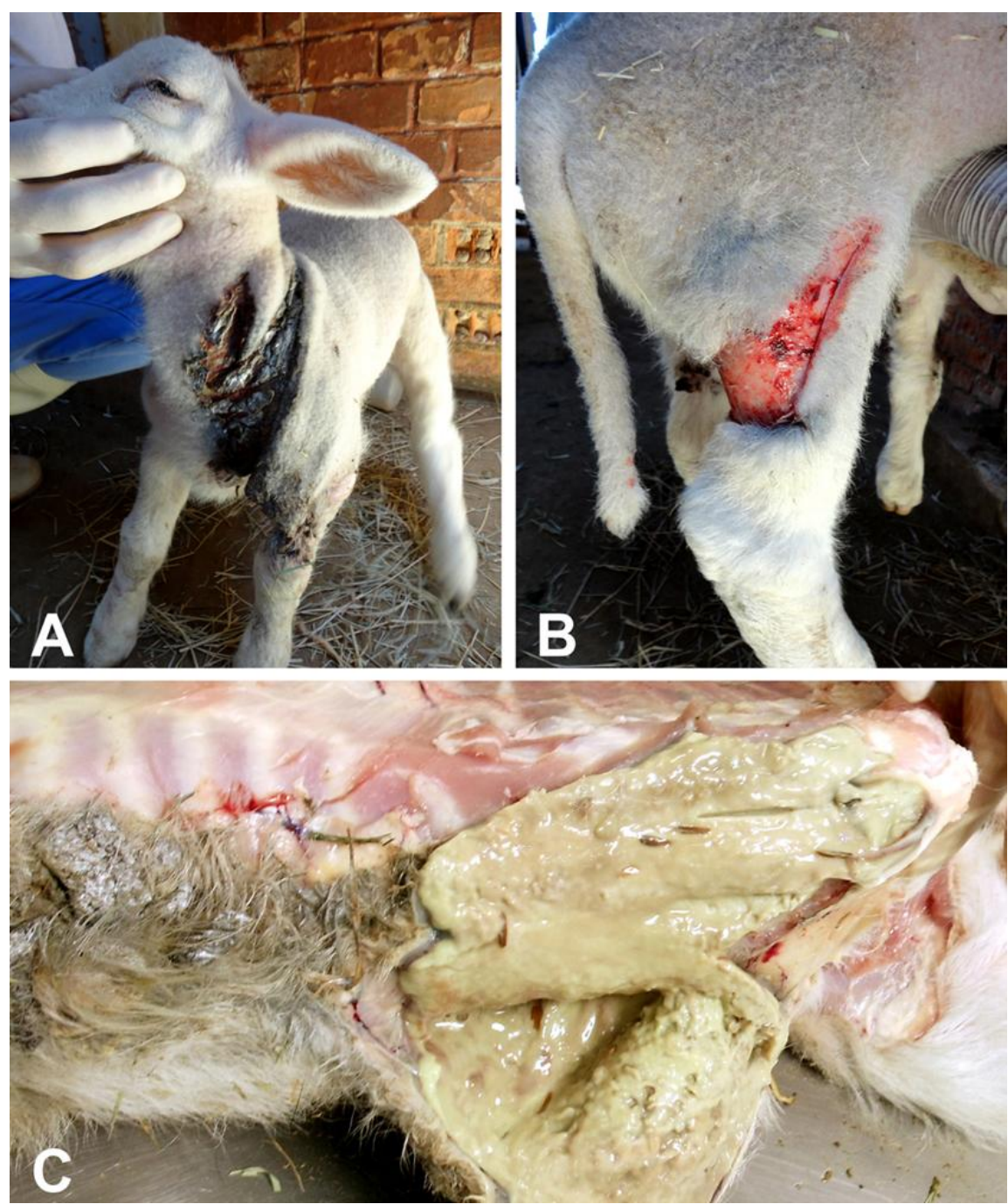

Figure 1. (A, B) Skin lacerations and flaps in a lamb with dermatosparaxis. (C) Cut surface of the subcutaneous tissues with a viscous purulent exudate, characterizing a phlegmon.

Microscopically, areas of laceration had an intense inflammatory infiltrate, composed predominantly of neutrophils in dermis and hypodermis, with accumulation of a large amount of fibrin, focally extensive necrosis containing bacterial colonies, and mild fibroplasia, characterizing a severe and focally extensive neutrophilic and necrotizing cellulitis and panniculitis. It is important to note that these were secondary lesions associated with cutaneous laceration, and intact skin of the affected lambs had no inflammatory reaction. Sections of intact skin from affected lambs had a dermal collagen with an aspect that resembles hyalinization, with poorly individualized, thin and disorganized collagen fibers (Figure 2A) that contrast with collagen fibers in the normal dermis (Figure 2B). Picro sirius stained sections were examined under polarized light, and demonstrated a change in the maturation pattern of collagen fibers. Under these conditions, the skin of a normal lamb exhibited abundant collagen fibers of distinct types, i.e. collagen types I and III, which are red and green under polarized light. In contrast, there was marked decrease in the amount of birefringent collagen fibers in the dermis of the affected lambs (Figure $2 \mathrm{~A}$ and 2B). Additionally, an increased amount of collagen with hyalinized appearance, without distinct collagen fibers, was observed around kidney blood vessels (Figure 2C and 2D) and liver of affected lambs. 

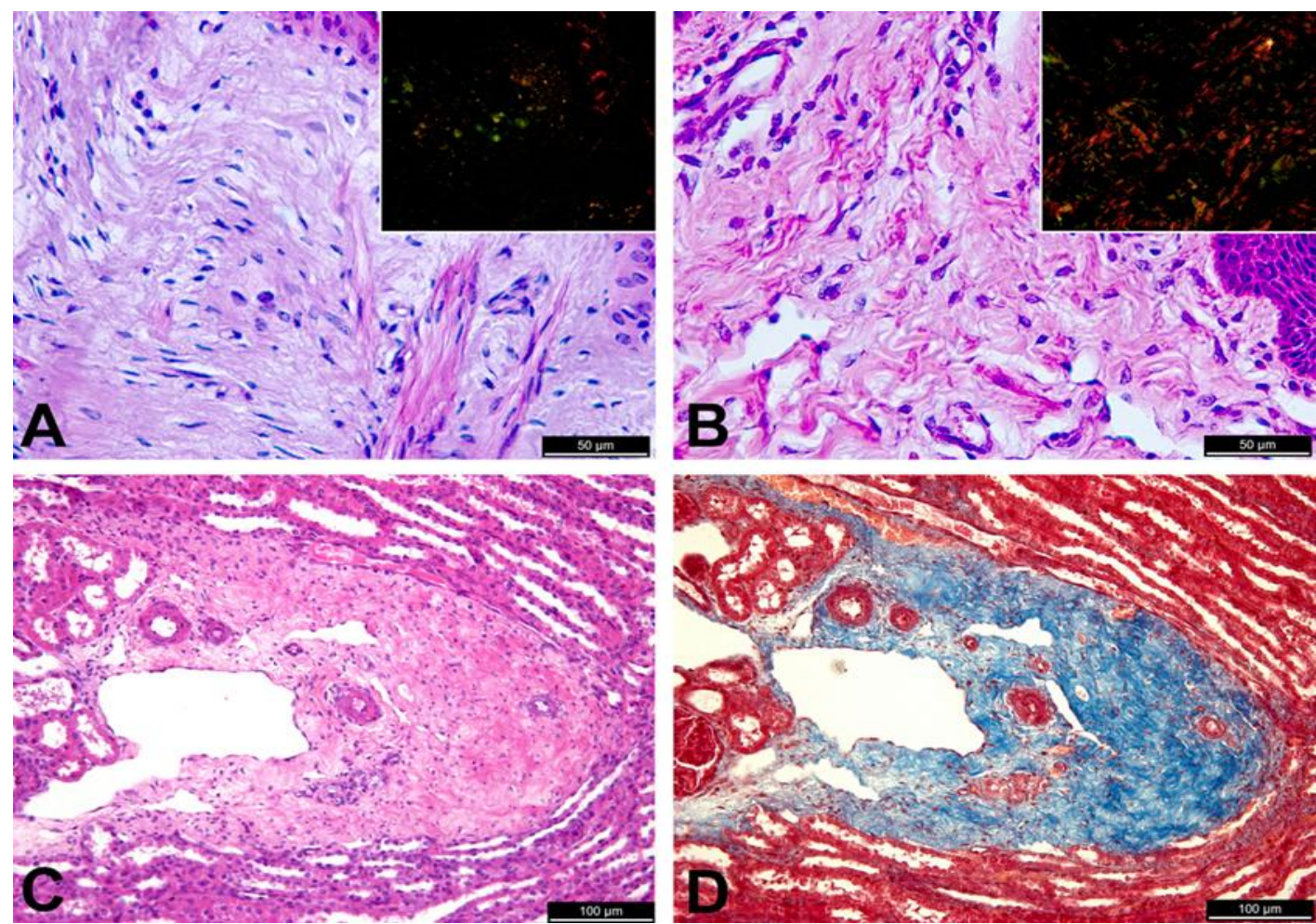

Figure 2. (A) Dermis of lamb with dermatosparaxis. Indistinct collagen fibers with foci of hyalinized appearance, $\mathrm{HE}$, bar $=50 \mu \mathrm{m}$; Inset: picro siruis stained section under polarized light with scarce birefringent collagen fibers. (B) Dermis from an unaffected lamb with distinct collagen fibers, HE, bar = $50 \mu \mathrm{m}$; Inset: picro siruis stained section under polarized light with abundance of type I collagen fibers. (C) Kidney with abundant perivascular connective tissue containing immature collagen fibers in a lamb with dermatosparaxis, HE, bar $=100 \mu \mathrm{m}$; and (D) Masson's trichrome, bar $=100 \mu \mathrm{m}$.

Ultrastructurally, dermal collagen fibrils in affected lambs were irregular and arranged in hieroglyphic shape with abundant amorphous substance, and they were not arranged in bundles (Figure 3A) as observed in non-affected lambs (Figure 3B). Scanning electron microscopy demonstrated numerous thin curly fibrils randomly arranged in the dermis of affected lambs (Figure 3C), whereas the normal dermis from the non affected lamb had fibrils uniformly arranged in bundles (Figure 3D).

\section{DISCUSSION}

Clinical, pathological, and microscopic findings reported here in two lambs are consistent with dermatosparaxis. This is the first report of ovine dermatoparaxis in Brazil. The disease in sheep has been reported in Norway (Fjolstad and Helle, 1974), Australia (Bavinton et al, 1985), South Africa (Van Halderen and Green 1988) and New
Zealand (Vaatstra et al., 2011). This disease is characterized by a marked fragility of the skin, which tears very easily (Vaatstra et al., 2011). Lacerations due to tearing of the skin were the most evident clinical sign observed in these cases. Although dermatosparaxis has no cure, and the skin lesions favor secondary bacterial infections that usually progress to a septic process, an accurate diagnosis is extremely important since it prevents new cases by identifying rams and ewes that are carriers of the mutated allele. A conclusive diagnosis of dermatosparaxis in sheep is established based on clinical signs and the abnormal ultrastructural morphology of collagen fibrils (Smith et al., 1992). As observed in this case, collagen fibers of affected lambs stained by Masson's trichrome are hyalinized and they do not stain as individualized bands as observed in the skin of normal lambs (Vaastra et al., 2011). 

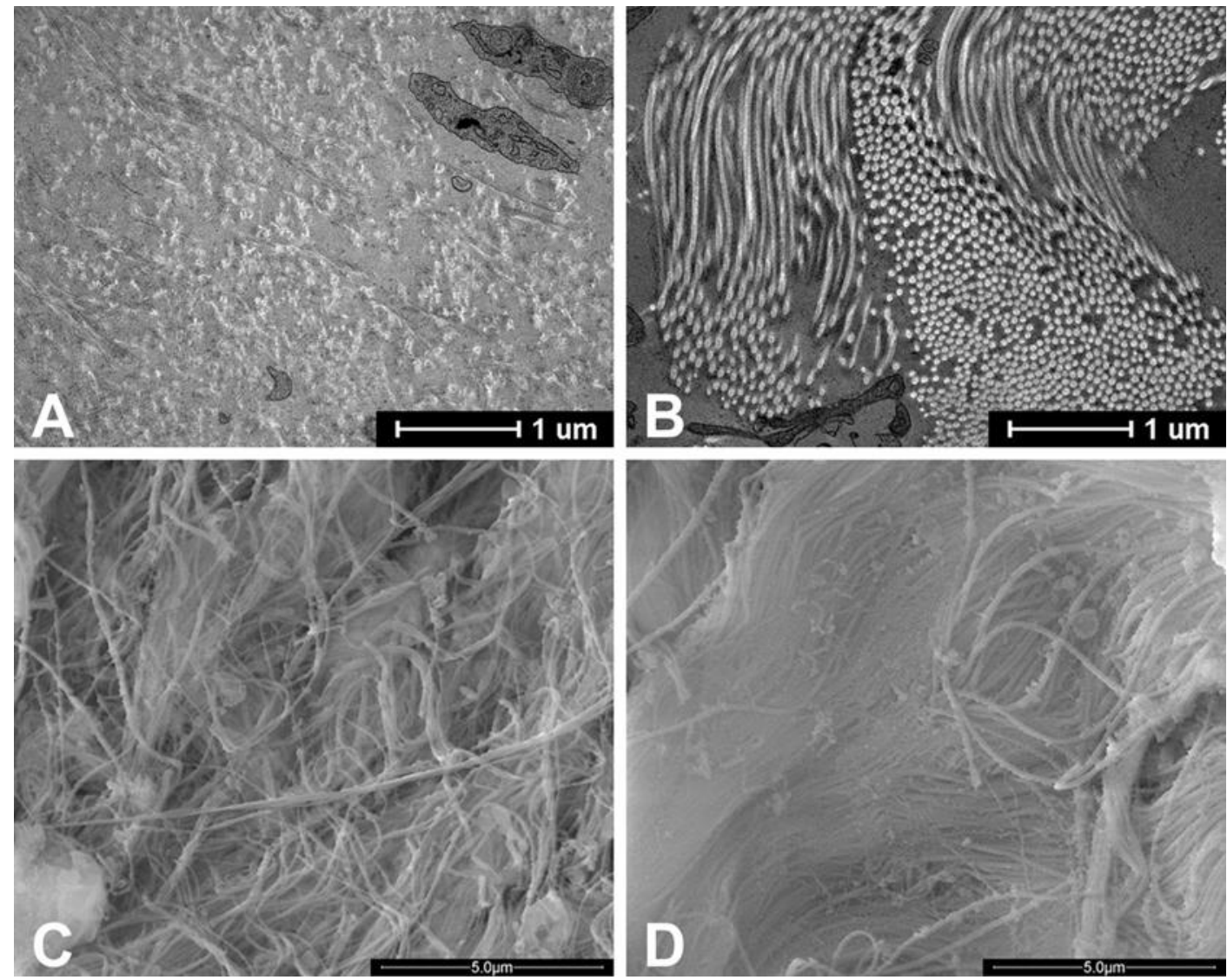

Figure 3. (A) Transmission electron microscopy. Cross section of the skin of a lamb with dermatosparaxis with disorganized collagen fibrils with hieroglyphic shape; and (B) collagen fibrils arranged in bundles in the dermis of a non affected lamb. (C) Scanning electron microscopy. Dermis of a lamb with dermatosparaxis with numerous thin and curly randomly arranged collagen fibrils; and (D) Dermis of a non affected lamb with collagen fibrils uniformly arranged in bundles.

The diagnosis of the two cases reported here was confirmed by transmission and scanning electron microscopy. Ultrastructurally, dermatosparaxis is characterized by atypically thin and irregular collagen fibrils (Van Halderen and Green 1988; Smith et al., 1992). These morphological changes are due to mutations in the ADAMTS-2 gene that prevent conversion of 1 pro-collagen to collagen, leading to accumulation of aminoterminal pro peptide molecules that confer hieroglyphic shape since there is no proper tensile strength in connective tissues under these conditions (Smith et al., 1992; Zhou et al., 2011). In other species, such as in the horse, dermatosparaxis is characterized by a hiperextensive and fragile skin with reduced amounts of dermal collagen. Fragmented and disorganized abnormal collagen fibers may be observed in trichrome stained sections. Abnormal collagen fibers may also be observed by electron microscopy (Gunson et al., 1984). The most significant clinical manifestation of the disease in humans is also cutaneous hyperextensibility (Smith et al., 1992).

Epidermolysis bullosa should be clinically considered as a differential diagnosis. Epidermolysis bullosa is a heritable disease that affects humans and animals, and it is characterized by blistering of the skin and mucous membranes after trauma. However, in sheep, the main area skin affected in this disease is over the dorsal region of carpus and tarsus (Ostmeier et al., 2012). In contrast to dermatosparaxis, in cases of epidermolysis bullosa, the epiderms is intact and there is subepidermal detachment of the epidermis that is associated with minimal inflammatory infiltrate. These features allow for a differential diagnosis based on morphologic differences between 
these diseases. Osteogenesis imperfecta is characterized by long bones with thickened diaphysis and no or small medullary cavity. It is associated with subcutaneous edema and joint laxity, with histopathological and ultrastructural evidences of a defect in collagen production (Arthur et al., 1992). Therefore, osteogenesis imperfecta must be considered in the differential diagnosis of dermatosparaxis (Vaastra et al., 2011).

In conclusion, this is the first reported case of demartosparaxis in sheep in Brazil. This diagnosis was extremely important for identifying carriers, thus preventing dissemination of the disease to other Brazilian ovine flocks.

\section{ACKNOWLEDGEMENTS}

Work in the RLS lab is supported by $\mathrm{CNPq}$ (Conselho Nacional de Desenvolvimento Científico e Tecnológico), FAPEMIG (Fundação de Amparo à Pesquisa do Estado de Minas Gerais), and CAPES (Coordenação de Aperfeiçoamento de Pessoal de Nível Superior). We thank the Center of Microscopy at the Universidade Federal de Minas Gerais for providing equipment and technical support.

\section{REFERENCES}

ARTHUR, D.G.; THOMPSON, K.G.; SWARBRICK, P. Lethal osteogenesis imperfecta and skin fragility in newborn Zealand Rommery lambs. $N$. Z. Vet. J., v.40, p.112-116, 1992.

BAVINTON, J.H.; PETERS, D.E.; RAMSHAW, J.A.M. A morphologic study of a mild form of ovine dermatosparaxis. J. Invest. Dermatol., v.84, p.391-395, 1985.

COLIGE, A.; SIERON, A.L.; LI, S.W. et al. Human Ehlers-Danlos syndrome type VIIC and bovine dermatosparaxis are caused by mutations in the procollagen IN-proteinase gene. Am. J. Hum. Genet., v.65, p.308-317, 1999.
FJOLSTAD, M.; HELLE, O. Hereditary dysplasia of collagen tissues in sheep. J. Pathol., v.112, p.183-188, 1974.

GUNSON, D.E.; HALLIWELL, R.E.; MINOR, R.R. Dermal collagen degradation and phagocytosis. Occurrence in horse with hyperextensible fragile skin. Arch. Dermatol., v.120, p.599-604, 1984.

KOHLER, H.B.K.; LUTKEFELS, E.; SOMMER-RADSCHAT, U. et al. EhlersDanlos like syndrome in a Pit-bull terrier mix. Tierarztl. Prax. K. H., v.30, p.123-127, 2002.

OSTMEIER M.; KERKMANN, A.; FRASE; M. Epidermolysis Bullosa (Herlitz Type) in German Black-Headed Mutton Sheep. J. Comp. Pathol., v.146, p.338-347, 2012.

SINKE, J.D.; VANDIJK, J.E.; WILLEMSE, T. A case of Ehlers-Danlos-like syndrome in a rabbit with a review of the disease in other species. Vet. Quart., v.19, p.182-185, 1997.

SMITH, L.T.; WERTELECKI, W.; MILSTONE, L.M. et al. Human dermatosparaxis - a form of the Ehlers-Danlos syndrome that results from failure to remove the amino-terminal propeptide of type-1 procollagen. Am. J. Hum. Genet., v.51, p.235-244, 1992.

VAATSTRA, B.L.; HALLIDAY, W.D.; WAROPASTRAKUL, S. Dermatosparaxis in two White Dorper lambs. N. Z. Vet. J., v.59, p.258-260, 2011.

VAN HALDEREN A.; GREEN, J.R. Dermatosparaxis in White Dorper sheep. $J$. $S$. Afr. Vet. Assoc., v.59, p.45-46, 1988.

ZHOU, H.; HICKFORD, J.G.H.; FANG, Q. A premature stop codon in the ADAMTS2 gene is likely to be responsible for dermatosparaxis in Dorper sheep. Anim. Genet., v.43, p.471-473, 2011. 